\title{
Therapeutic management of Ehrlichiosis in German Shepherd Dog: A Case Reports
}

\author{
Y. P. Maheshwarappa*, Shivanagouda S Patil, C. R. Swapna, \\ M. Chandrashekarappa, A. M. Kotresh and B. S. Pradeep
}

*Corresponding author

K e y w o r d s
edema of the
scrotum and all
limbs food intake,
dullness

\section{A B S T R A C T}

A 3-year-old male German Shepherd dog weighing $26 \mathrm{~kg}$ is presented to Referral Veterinary Polyclinic and Teaching Veterinary Clinical Complex, ICAR- IVRI, Izatnagar, with the history of reduced food intake, dullness, weakness in all limbs since 1 week, edema of the scrotum and all limbs since 3 days. Clinical examination revealed elevated rectal temperature$104.30 \mathrm{~F}$, tachycardia, increased respiratory rate, pale mucous membrane along with ticks over the body was noticed. Haematological examination showed decreased RBC count-1.93million/cmm, Leucocyte count$8100 / \mathrm{cmm}$, Neutrophils- $75.6 \%$, lymphocyte count-20.6\%, Monocyte count$3.8 \%$, decreased HB- $4.9 \mathrm{~g} \%$, Thrombocytopenia-80000/microlitre. Serum biochemistry has shown normal Creatinine value $-1.1 \mathrm{mg} / \mathrm{dl}$ and elevated SGPT value-218 IU/L. On blood smear examination with Giemsa staining, Ehrlichia Morulae were noticed in Monocytes suggestive of Canine Ehrlichiosis.

\section{Introduction}

Tick-borne diseases represent a problem of growing importance for public health (Parola et al., 2000). Ehrlichia canis is an obligate intracellular rickettsial agent that is transmitted by a brown dog tick i.e. Rhipicephalus sanguineus which is considered as the principal vector of this disease. ( Ristic and Holland, 1993). The disease is characterized by a wide variety of clinical signs of which depression, lethargy, weight loss, anorexia, pyrexia, lymphadenomegaly, splenomegaly, and bleeding tendencies are the most common. Major hematologic abnormalities comprise of thrombocytopenia, mild anemia, and mild leukopenia during the acute stage, mild thrombocytopenia in the subclinical stage, and pancytopenia in the severe chronic stage. The main biochemical abnormalities include hypoalbuminemia, hyperglobulinemia, and hypergammaglobulinemia (Harrus et al., 1997). 
The most common and consistent hematological abnormality of dogs infected with E. Canis naturally or experimentally is thought to be thrombocytopenia (Waner et al., 1995). Mechanisms assumed to be involved in the pathogenesis of thrombocytopenia in the acute phase of the disease include increased platelet consumption due to inflammatory changes in blood vessel endothelium, increased splenic sequestration of platelets, and immunologic destruction or injury resulting in a significantly decreased platelet life span (Kakoma et al., 1978). E. canis causes a potentially fatal disease in dogs that requires rapid and accurate diagnosis to initiate appropriate therapy leading to a favorable prognosis (McBride et al., 2001).

\section{Materials and Methods}

A 3-year-old male German Shepherd dog weighing $31 \mathrm{~kg}$ is presented to Referral Veterinary Polyclinic and Teaching Veterinary Clinical Complex, ICAR- IVRI, Izatnagar, with the history of reduced food intake, fever, dullness, weakness in all limbs since 1 week, edema of scrotum and limbs since last 3 days. Deworming and Vaccination history was proper.

Clinical examination revealed elevated rectal temperature-104.30

$\mathrm{F}$, Tachycardia(155beats/min), increased respiratory rate, Hepatomegaly, peripheral Lymphadenopathy, pale conjunctival and oral mucous membrane along with ticks noticed over the body. Blood and serum samples were collected for hematology and serum biochemistry, respectively.

The peripheral blood smear was prepared and stained with Giemsa stain after methanol fixation (Sathpathi et al., 2014). The stained blood smear was screened for haemoprotozoa under the light microscope. Haematological analysis was carried out as per the standard method (Jain, 1986). Biochemical analysis was done with a semi-autoanalyzer. The hemato-biochemical values were compared with normal reference values and interpreted.

\section{Results and Discussion}

The Haematological analysis revealed anaemia (decreased level of Haemoglobulin, and red blood cell), Thrombocytopenia, normal leucocyte count with neutrophilia. The serum biochemistry showed normal Creatinine value, elevated Alanine aminotransferase (ALT. The detailed haematological and serum biochemical parameters before therapy and after therapy are mentioned in Table 1. The stained peripheral blood smear was positive for Ehrlichia morulae in monocytes (Fig. 1). Based on history, clinical and laboratory findings it was diagnosed as a case of Canine Ehrlichiosis.

The treatment was started with Tab. Doxycycline @ $5 \mathrm{mg} / \mathrm{kg}$, PO, BID for 28 days. For the management of ticks Fiprofort spot on was applied. Supportive treatment was done with Inj. NS @ $200 \mathrm{ml}$ very slow IV, Inj. Meloxicam @ $0.5 \mathrm{mg} / \mathrm{kg}, \mathrm{IM}, \mathrm{BID}$, Inj. Ranitidine@ $1 \mathrm{mg} / \mathrm{kg}, \mathrm{SC}, \mathrm{TID}, \mathrm{Inj}$. Eldervet@2ml, IV was given for 3 days. Along with this, Tab.Wysolone @ $1 \mathrm{mg} / \mathrm{kg}$ bodyweight for 5 days followed by $0.5 \mathrm{mg} / \mathrm{kg}$ for next 5 days (Tapering dose), Hematinic (Syp. aRBC pet @ $10 \mathrm{ml}$, PO, BID) and Hepatoprotectant (Syp.Liv-52@10 ml, PO, BID) Syrup. Thromb beat @ 10ml BID PO was given for 4 weeks. After 4 weeks of therapy, the dog showed marked improvement in condition. Haematobiochemical values were found within a normal range and peripheral blood smear was negative for $E$. canis on the 28th day of posttherapy. 
Table.1 Haemato-biochemical changes in a dog before and after therapy

\begin{tabular}{|c|c|c|c|c|}
\hline \multicolumn{5}{|c|}{ Haematological Parameters } \\
\hline Parameter & Day 0 & Day 28 & $\begin{array}{l}\text { Reference } \\
\text { range* }\end{array}$ & Key findings \\
\hline $\begin{array}{l}\text { RBC count } \\
\left(\mathbf{m i l l i o n s} / \mathbf{m m}^{3}\right)\end{array}$ & 2.79 & 6.27 & $5.0-7.9$ & \multirow[t]{2}{*}{ Anaemia } \\
\hline Hemoglobin (g/dl) & 6.3 & 13.2 & $12-19$ & \\
\hline $\begin{array}{l}\text { Total WBC count }\left(10^{3}\right. \\
\left.\text { cells } / \mathbf{m m}^{3}\right)\end{array}$ & 8.6 & 11.3 & $5.0-14.1$ & \\
\hline Neutrophils (\%) & 87 & 72 & $58-85$ & Neutrophilia \\
\hline Lymphocyte (\%) & 7.2 & 22.5 & $8-21$ & \\
\hline Monocytes (\%) & 3.8 & 3.5 & $2-10$ & \\
\hline Eosinophils (\%) & 2 & 2 & $0-9$ & \\
\hline Basophils (\%) & 0 & 0 & $0-1$ & \\
\hline Platelets (lakhs/mm³) & 0.8 & 1.86 & $2.11-6.21$ & Thrombocytopenia \\
\hline \multicolumn{5}{|c|}{ Serum Biochemical Parameters } \\
\hline Parameter & Day 0 & Day 28 & $\begin{array}{l}\text { Reference } \\
\text { range\# }\end{array}$ & \\
\hline ALT (U/L) & 218.8 & 127.9 & $10-109$ & $\begin{array}{l}\text { Elevated-liver } \\
\text { specific enzyme }\end{array}$ \\
\hline Creatinine (mg/dl) & 1.12 & 0.871 & $0.5-1.7$ & \\
\hline
\end{tabular}

* March 2012: Haematology reference ranges, 10th edn. The Merck Veterinary Manual

\# March 2012: Serum biochemical reference ranges, 10th edn. The Merck Veterinary Manual

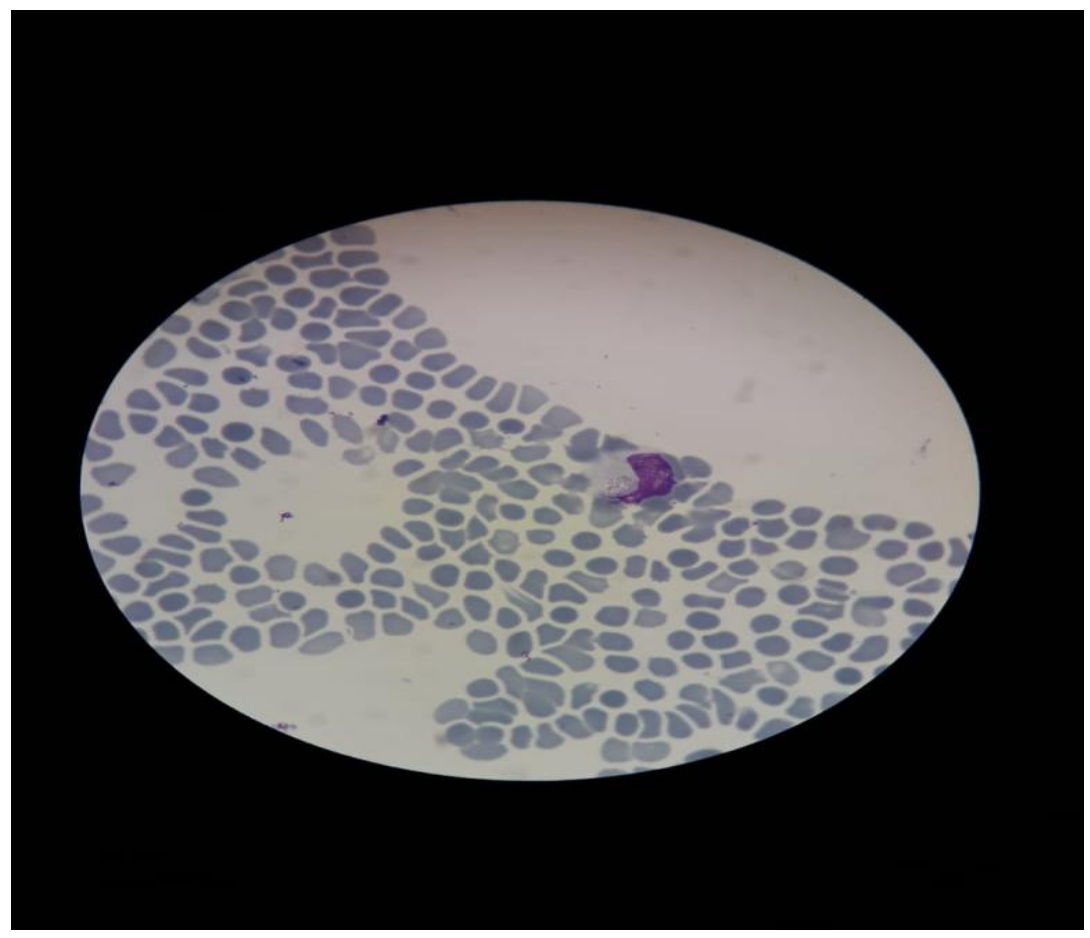

Fig.1 Ehrlichia canis morula (arrow) in monocyte (Giemsa stain) 
The exact pathogenesis of CME remains unknown. It has been suggested as a mechanism for pathologic alterations and clinical signs are due to Immunologic dysfunction. Increased production of interleukin-1 (IL-1) by antigen-presenting cells and B cells or exogenous pyrogen products of the parasite are responsible for Fever and some clinical signs and symptoms observed in all infected dogs (Gershwin et al., 1995).

These alterations were already manifest between days 10 and 14 after infection, similar to the findings reported in naturally infected and dogs experimentally exposed to E. canis by (Huxsoll et al., 1972) and (Pierce et al., 1977), respectively. The clinical findings such as pale mucous membranes, hepatomegaly, lymphadenopathy, splenomegaly, emaciation, increased hair loss and hematological alterations observed in these infected animals have been previously reported in cases of canine ehrlichiosis (Hoskins, 1991; Troy and Forrester, 1990).

Thrombocytopenia, leucopenia, and anemia are most frequently observed in CME (Hoskins, 1991; Davoust et al., 1991). Infected dogs presented mild to moderate hematological changes in acute experimental infection for just a few weeks. The tendency for the hematological parameters to return to normal was evident at the end of the experiment. This result may be a consequence of transient suppression of bone marrow activity due to $E$. canis infection (Buhles et al., 1975).

It has been assumed that the pathogenesis of thrombocytopenia is due to Anti-platelet antibodies produced in CME (Harrus et al., 1996). Anemia may explain the observed paleness of mucous membranes and most organs. Lymphadenopathy, splenomegaly, ascites, paleness of mucous membrane, kidney and liver, and discrete pulmonary congestion were observed at the necropsy of inoculated dogs as has been previously reported in cases of canine ehrlichiosis (Hildebrandt et al., 1970; Hildebrandt et al., 1973 ). observed the same in German Shepherd dogs and posited breed susceptibility (Nyindo et al., 1980).

\section{References}

Buhles, W. C., Huxsoll, D. L. and Hildebrandt, P. K. 1975. Tropical Canine Pancitopenia: role of aplastic anemia in the pathogenesis of severe disease. J. Comp. Pathol. 85, 511-521.

Davoust, B., Parzy, D., Vidor, E., Hasselot, N. and Martet, G. 1991. Ehrlichiose Canine Experimentale: etude Clinique et therapeutique. Rec. Med. Vet. 167, 33-40.

Gershwin, L. J., Krakowka, S. and Olsen, R. G. 1995. Cytokines. In: Immunology and Immunopathology of Domestic Animals, $2^{\text {nd }}$ ed. Mosby. St. Louis. 4046.

Harrus, S., Waner, T. and Bark. H. 1997. Canine monocytic ehrlichiosis - an update. Comp. Cont. Ed. Prac. Vet. 19, 431- 444.

Harrus, S., Waner, T., Weiss, D. J., Keysary, A. and Bark, H. 1996. Kinetics of serum antiplatelet antibodies in experimental acute canine ehrlichiosis. Vet. Immunol. Immunopathol. 51, 13-20.

Hildebrandt, P. K., Huxsoll, D. L. and Nims, R. M. 1970. Experimental ehrlichiosis in young Beagle dogs. Fed. Proc. 29, 754.

Hildebrandt, P. K., Huxsoll, D. L., Walker, J. S., Nims, R. M., Taylor, R. and Andrews, M. 1973. Pathology of canine ehrlichiosis (Tropical canine pancytopenia). Am. J. Vet. Res. 34, 1309-1320.

Hoskins, J. D. 1991. Ehrlichial diseases of dogs: diagnosis and treatment. Canine 
Pract. 16, 13-21.

Huxsoll, D. L., Amyx, H. L., Helmet, I. E., Hildebrandt, P. K., Nims, R. M. and Gochenour. W. S. 1972. Laboratory studies of Tropical Canine Pancytopenia. Exp. Parasitol. 31, 53-59.

Jain. N. C. 1986. Schalm's Veterinary Hematology. Fourth ed., Lea and Febiger, Philadelphia.

Kakoma, I., Carson, C. A., Ristic, M., Stephenson, E. M., Hildebrandt, P. K. and Huxsoll, D. L. 1978. Platelet migration inhibition as an indicator of immunologically mediated target cell injury in canine ehrlichiosis. Infect. Immun. 20, 242-247.

McBride, J., Corstvet, R., Breitschwerdt, E. and Walker, D. 2001. Immunodiagnosis of Ehrlichia canis Infection with Recombinant Proteins. J. Clin. Microbiol. 39, 315-322.

Nyindo, M., Huxsoll, D. L., Ristic, M., Kakoma, I., Brown, J. L., Carson, C.A. and Stephenson, E. H. 1980. Cellmediated and humoral immune response of German shepherd dogs and beagles to experimental infection with Erlichia canis. Am. J. Vet. Res. 41, 250-254.

Parola, P., Roux, V., Camicas, J-L., Baradji, I., Brouqui, P. and Raoult, D. 2000.
Detection of ehrliciae in African ticks by polymerase chain reaction. Trans. R. Soc. Trop. Med. Hyg. 6, 707-708.

Pierce, K. R., Marrs, G. E. and Hightower, D. 1977. Acute canine ehrlichiosis: platelet survival and factor 3 assay. Am. J. Vet. Res. 38, 1821-1825.

Ristic, M. and C. J. Holland. 1993. Canine ehrlichiosis In Z. Woldehiwet and M. Ristic (ed.), Rickettsial and chlamydial diseases of domestic animals. Pergamon Press, Oxford, United Kingdom. 169186.

Sathpathi. S., Mohanty, A. K., Satpathi, P., Mishra, S. K., Behera, P. K., Patel G. 2014. Comparing Leishman and Giemsa staining for the assessment of peripheral blood smear preparations in a malariaendemic region in India. Malaria. journal. 13 (1): 512.

Troy, G. C. and Forrester, S. D., 1990. Canine Ehrlichiosis. In: Greene, C.E., Infectious Diseases of the Dog and Cat. W.B. Saunders, Philadelphia, 48-59.

Waner, T., Harrus, S., Weiss, D. J., Bark, H. and Keysary, A. 1995. Demonstration of serum antiplatelet antibodies in experimental acute canine ehrlichiosis. Vet. Immunol. Immunopathol. 48, 177182.

\section{How to cite this article:}

Maheshwarappa. Y. P., Shivanagouda S Patil, C. R. Swapna, M. Chandrashekarappa, A. M. Kotresh and Pradeep. B. S. 2020. Therapeutic management of Ehrlichiosis in German Shepherd Dog: A Case Reports. Int.J.Curr.Microbiol.App.Sci. 9(03): 2440-2444. doi: https://doi.org/10.20546/ijcmas.2020.903.279 